\title{
Chapter 20 \\ Routes Beyond Gandhara: Buddhist \\ Rock Carvings in the Context \\ of the Early Silk Roads
}

\author{
Marike van Aerde
}

\begin{abstract}
This chapter presents the first results and interpretations of a selected dataset of rock carvings from the Karakorum mountains. The research is focused on early Buddhist carvings and their spread and role within networks of the early Silk Roads in Central Asia from the 2nd-1st century BCE. The rock carvings and their archaeological context are studied to gain insight into routes from Gandhara through the Karakorum range. The first part presents the general aims and relevance. The second and third parts describe the analysis and interpretation of the Karakorum dataset, followed by the main points of discussion and conclusions to incite future investigations.
\end{abstract}

Keywords Silk Roads $\cdot$ Buddhism $\cdot$ Rock carvings $\cdot$ Karakorum $\cdot$ Gandhara Dynamic networks

\subsection{Introduction}

Concepts that have proven useful in ordering things easily achieve such authority over us that we forget their origins and accept them as unalterable givens. The path of scientific progress is often made impassable by such errors.

-Albert Einstein ${ }^{1}$

As early as 1916, Albert Einstein remarked on a pressing epistemological issue still faced by scholars and scientists today: the methodological necessity to create categorised concepts in order to study reality, paired with our subsequent tendency

\footnotetext{
${ }^{1}$ A. Einstein (1916), Physikalische Zeitschrift 17, 101: 'Begriffe, welche sich bei der Ordnung der Dinge als nützlich erwiesen haben, erlangen über uns leicht eine solche Autorität, dass wir ihres irdischen Ursprungs vergessen und sie als unabänderliche Gegebenheiten hinnehmen. Der Weg des wissenschaftlichen Fortschritts wird durch solche Irrtümer oft für längere Zeit ungangbar gemacht'.
}

M. van Aerde ( $\otimes)$

Faculty of Archaeology, Leiden University, Einsteinweg 2, 2333 CC Leiden, The Netherlands

e-mail: m.e.j.j.van.aerde@ arch.leidenuniv.nl

L. E. Yang et al. (eds.), Socio-Environmental Dynamics along the Historical Silk Road, https://doi.org/10.1007/978-3-030-00728-7_20 
to come to regard those predetermined categories as truths. The initial 19th/20thcentury campaigns of Gandharan archaeology (modern-day Afghanistan to northern India and Pakistan, cf. Foucher 1905; Cunningham 1871; Marshall 1975) were often marked by this tendency, as evident from John Marshall's own words upon starting his campaign at the site of Taxila: 'At that time I was a young man, fresh from archaeological excavations in Greece and filled with enthusiasm for anything Greek, and in that far-off corner of the Punjab it seemed as if I had lighted of a sudden on a bit of Greece itself' (Marshall 1975, Xv). In particular, connections were sought between Buddhist material culture and the Hellenistic presence. The earliest-known anthropomorphic depictions of the Buddha originate from the Gandhara region, and these statues were particularly noted for their 'Greek' or 'Hellenistic' style. These initial campaigns focused on the 'Greek' style of Buddhist sculptures and reliefs, generally with the intent to demonstrate that the arrival of Hellenistic settlers in Gandhara, especially in the form of the Indo-Greek kingdoms (one of the first founders was Menander I in 130-131 BCE), became a 'superior filter' for the local Buddhist culture (Bussagli 1984, 161-165). This approach resulted in the stylistic category and ethic-cultural container of 'Greco-Buddhist art', which was usually subdivided by means of multiple sub-categories, e.g., 'proto-Hellenic Buddhist art' or 'barbaric Afghan style', in order to keep fitting the diversity of finds from Gandharan sites into this preconceived Greco-Buddhist container (Marshall 1975 II, 520-521).

Since the mid-20th century, new archaeological, historical and epigraphical investigation have added important new insights into the complexity of both Gandharan and early Buddhist archaeology, especially pertaining specific sites and contexts within the Gandhara region and the remarkable diversity of intercultural material culture encountered there (Faccenna 1980; Bussagli 1996; Behrendt 2007; Boardman 2015; Facenna and Taddei 1993; Verardi and Filigenzi 2003; Mairs 2014). In order to continue this trend, it is imperative to keep challenging the more traditional culture-container categorisations that once marked this field. The present chapter endeavours to do this by focusing on the relatively neglected dataset of early Buddhist rock carvings from the Karakorum mountain range between Gandhara and the Tarim Basin (Xinjiang, China). These carvings appear to (literally) take early Buddhist iconography and architectural styles, many of which specifically known from Gandhara, beyond that region. In doing so, the analysis works towards new archaeological evidence for specific mountain routes as part of the Silk Roads networks from the 2nd-1st century BCE onwards. By focusing on Buddhist carvings specifically, the role of Buddhism within this dynamic network is put central.

This contribution presents the first results of the investigation, and as such aims to function as a basis for the continuation and expansion of research into the Karakorum rock carvings datasets. The methodology uses a bottom-up approach to the data and bases subsequent findings and discussion on the results of the data analysis. In doing so, this study also addresses the issue of compartmentalisation that has remained long rooted in the methodological division between cultural studies and archaeological contexts that also include environmental factors. These are crucial especially for the dynamic archaeological record of the early Silk Roads networks. Frequently, interpretations of these early routes have followed narratives of a linear 
trade networks (referring to an ancient 'Silk Road', indicating a singular route) that stretched between two main dominant powers, the Roman Empire in the West and the Imperial Chinese Dynasties in the East, even though these two powers never actually, physically connected. ${ }^{2}$ The only way to go beyond such dualist approaches to ancient Silk Roads archaeology, is to study the archaeological evidence of these early networks by focusing on the places in between-of which the Karakorum mountain routes may be a prime example and valuable source of information.

In order to achieve this, this study adopts a change of perspective for Gandharan archaeology in specific. Traditionally, studies predetermined or newly devised certain (cultural and/or ethnic) 'containers' to organise the data and thus enable interpretations from a top-down approach. In contrast, this research approaches the diverse data as variables of the dynamic networks of the ancient Silk Roads and hence bases any hypotheses and interpretations on the patterns and/or insights that these variables may reveal when studied empirically and within the scope of both their archaeological and environmental contexts. The analysis pertains to the iconography as well as carving methods of the relevant rock carvings, their archaeological contexts, and their distribution as part of the physical environment of the Karakorum mountains where they were encountered. For the latter, analysis of recent satellite footage has been used.

The second section provides a literature review of the Karakorum rock carvings, concerning their documentation and preliminary interpretations up until now. The third section presents the analysis results and discusses them, interpreting the carvings in terms of (1) their Buddhist iconography in comparison to early Gandharan Buddhist material culture, and (2) the significance of these carvings for reconstructing routes through the Karakorum mountains based on empirical evidence. The final section pertains the conclusion and explores next steps for continuing the research.

\subsection{Early Buddhist Archaeology and the Karakorum Rock Carvings}

The Karakorum mountain range borders modern-day India, Pakistan and China (Fig. 20.1). It includes the Gilgit-Baltistan region in Pakistan, the Ladakh region in India, and the south-western Xinjiang region of China, and is part of the western

\footnotetext{
${ }^{2}$ Despite the fact that no direct contact was ever made between Han China and Rome, the Han elite in particular was very interested in luxury products from the West and in particular from the Roman Empire (the discovery of an apparently Roman tapestry at Loulan in the Taklamakan desert excavated among Han silks suggests such a trade in Roman goods; Liu 2010, 18-19; Yu 1967), and a similar interest in Rome is recorded in several sections of the Hou Hanshu, the Book of the Later Han (for a recent translation and study of its implications for Silk Road studies, see Hill 2009). The Han even sent an envoy, Gan Ying, to learn more about the Romans, but he never arrived due to interceptions (most likely by Parthians) at the Red Sea (See: Beckwith 2009, 78-92; Liu 2010, 19; and most recently Poo et al. 2017). See also Miller (2014, 1-43) and Miller and Brosseder (2017, 470-487) for arguments against a dualist East-West approach in Silk Roads archaeology.
} 


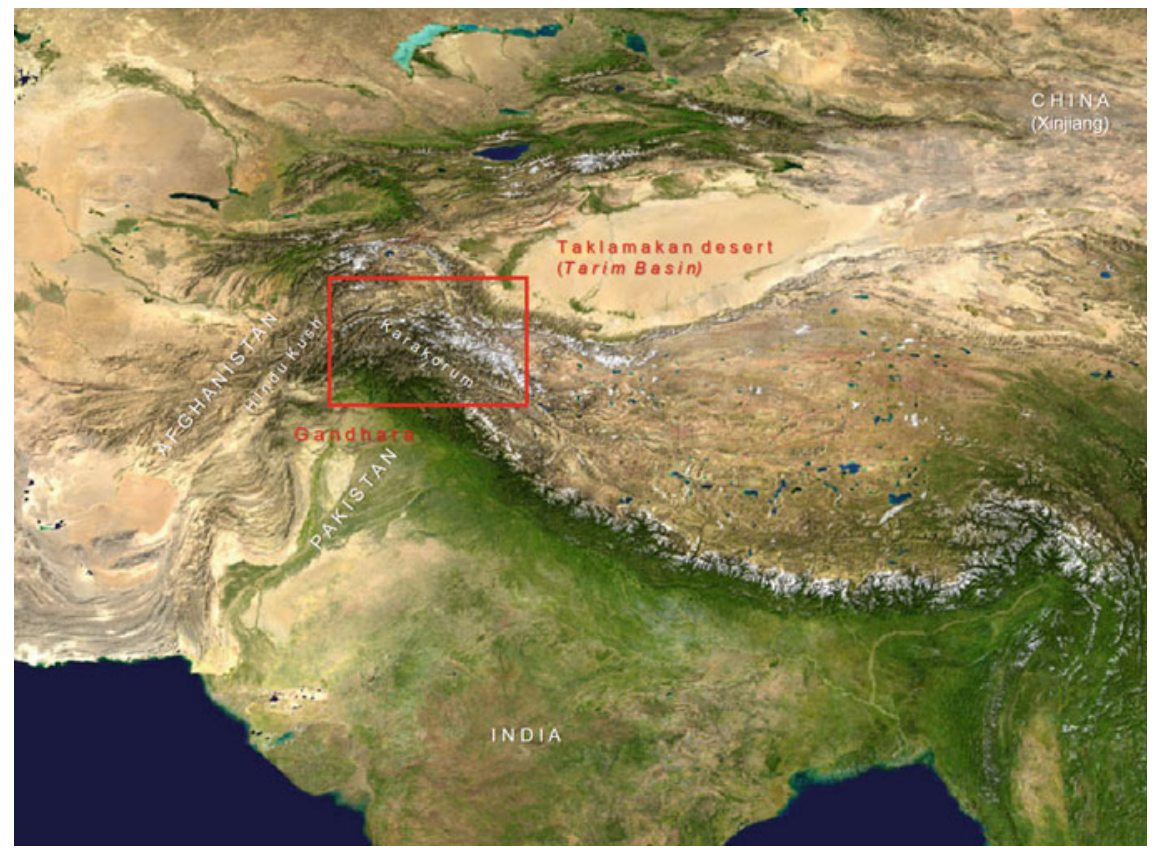

Fig. 20.1 Area of the Karakorum Mountains investigated as indicated in the square. Satellite footage NASA 2014

edge of the Himalayas along with the Hindu Kush range bordering Pakistan and Afghanistan in the West. From 1979 onwards, the Karakorum Highway (also known as the China-Pakistan Friendship Highway) has increased mobility between Pakistan and western China, and this likewise enabled accessibility to remoter mountain regions for archaeological campaigns. The presence of ancient rock carvings and epigraphy in the Karakorum mountains (then also known as the eastern Hindu Kush) was first noted by Hungarian adventurer Karl Eugen in 1884, who remarked on Buddhist carvings in the Baltistan area, and by Pakistani explorer Ghulam Muhammed in 1907, who visited the lower region of Diamer (Jettmar 1989; Fussman and Jettmar 1994; Hauptmann 2009). But no systematic or scholarly documentation occurred until the early twentieth century; between 1900 and 1944 Aurel Stein studied a concise but at that time unique sample of carvings (Stein 1944, 5-24). But only from 1979 onwards larger-scale explorations and documentations were possible because of the Karakorum Highway, and these campaigns have yielded a substantial data set of carvings. ${ }^{3}$

\footnotetext{
${ }^{3}$ As documented in the Materien zur Archaologie der Nordgebiete Pakistanscatalogues (MANP) catalogues, Band 1-11, edited by Gérard Fussman, Karl Jettmar, Ditte König et al. between 1989 and 1994, and more recently re-edited and published by Harald Hauptmann from 2003 to 2011, as part of the Heidelberg Academy. For the research described in this paper, I was able to access MANP Band 1, 2, 6-11.
} 
Initiated by Karl Jettmar, these campaigns were overseen by the German Research Council and subsequently by the Heidelberg Academy. The long-running project entitled 'Rock Carvings and inscriptions along the Karakorum Highway' was initiated in 1983 as collaboration between the Department of Archaeology of Gilgit and the Heidelberg Academy. ${ }^{4}$ From 1989 until 2013, Harald Hauptmann has overseen the continuing documentation of rocks carvings as well as the excavation of archaeological sites in these mountain range, especially in the Gilgit-Baltistan region. ${ }^{5}$ Hauptmann confirms that the connections between Gandhara and the Silk Roads beyond the Hindu Kush and Karakorum mountain ranges, such as indicated by the Karakorum data since 1979, have been often neglected by more interpretative scholarship so far and represent 'ein ebenso altes wie dringendes Forschungsdesiderat' 6 Unfortunately, recent plans for rescue excavations before the planned construction of the Diamer-Basha dam, not far west of the Chilas area along the Indus River, have been restricted: as confirmed by Hauptmann, the construction of this dam will inundate an estimate of at least 37,051 carvings on 5928 boulders or rock faces. $^{7}$ In addition, the region including the field stations at Chilas, Thalpan and Oshibat has become less accessible since 2013 due to increasing political unrest (which has already led to ancient carvings being vandalised, partially removed or destroyed in the region) and the likewise increased planning of corporate building projects following the Diamer-Basha dam; moreover, a lack of centrally organised research funding in Pakistan has made large-scale projects difficult at present, despite the presence of available expertise and many sites and data left to explore and document. ${ }^{8}$

However, the documented Karakorum rock carving data so far is substantial and give us a significant amount of material to work with at present. Hauptmann is currently preparing a synthesis of the archaeology and early history of the Upper Indus Region in overview, which will help future studies to connect sites as well as apply wider frameworks for interpretation. The available documentation from the Karakorum field stations so far has been thoroughly collected, yet due to the general lack of attention paid to these data by studies that consider wider historical contexts of the region, especially those concerning Silk Roads contexts and connections with Gandhara, there remains a lack of in-depth interpretative studies that incorporate these data sets. This paper looks at a selection of these data as primary sources (Sects. 3.2-4) to arrive at new insights not only into the mountain passes themselves and the diversity

\footnotetext{
${ }^{4}$ As documented and discussed in: Jettmar (1985, 1989, 1993), Fussman (1994), Bennmann and König (1994), Fussman and Bandini-König (1997), Bandini-König (2003, 2005, 2007, 2009, 2011 , 2013), Hauptmann (2009).

${ }^{5}$ This included the re-editing of MANP vol. 1-11, as well as additional (incl. forthcoming) publications (Hauptmann 2009). Information was shared in personal communication with Prof. Hauptmann in Heidelberg, 2017.

${ }^{6}$ Cited from personal communication with Prof. Hauptmann.

${ }^{7}$ Cited in Pakistani newspaper Dawn (article by S. Yusuf, May 18, 2011) and from personal communication with Prof. Hauptmann.

${ }^{8}$ The above-cited International Conference on the Archaeological Heritage of Pakistan: Challenges, Potential and the Way Forward (20-22 October 2017, Lahore), is one initiative of the Pakistan's Higher Education Commission to tackle inherent issues.
} 
of people that travelled through them, but also into these Karakorum routes as part of wider ancient Silk Road trade patterns. A selection of the data is necessary because of the great number as well as the remarkable diversity encountered in these rock carvings: apart from the many textual inscriptions (in languages varying from early Kharosthi to Chinese and with topics, when discernible, ranging from early Buddhist epigraphy to caravan travel notes), ${ }^{9}$ there are carvings depicting wild animals and natural environments recognisable from the surrounding mountains (generally identified as prehistorical carvings), ${ }^{10}$ decorative motifs that have generally been grouped together as belonging to 'Eurasian nomadic cultures', ${ }^{11}$ decorative/symbolic Persian motifs, ${ }^{12}$ and scenes of human life in the mountains (especially depicting travelling caravans and hunters with dogs, generally included in either the prehistoric or nomadic groupings). ${ }^{13}$ But perhaps the most visually striking type of carvings in the data set and containing the largest-sized imagery discovered in these mountains so far, is Buddhist imagery.

The two prominent themes encountered in these Buddhist carvings are (1) architecture of traditional early Buddhist stupa monuments, and (2) anthropomorphic depictures of the Buddha with scenes from his life and followers. Despite the thorough documentation of these carvings in the Heidelberg Academy publications, contextual interpretations beyond the mountain sites have been limited beyond the studies of scholars directly involved with the project. Between 1989 and 1994, three volumes of Antiquities of Northern Pakistan (ANP) were published as part of the 'Rock Carvings and Inscriptions along the Karakorum Highway' project, edited by Karl Jettmar and Gérard Fussman, which contain in-depth analysis of the documented data, mainly concerning textual interpretations and determination of different carving types and chronologies as based on the available sources and the scholars' hypotheses (ANP Vol. 1-3: Jettmar 1989, 1993; Fussmann and Jettmar 1994). In their studies of the Karakorum carvings, Fussman as well as Oskar von Hinüber focused on the early Buddhist period, but predominantly concerning documentation of Kharosthi and Brahmi inscriptions that accompanied a variety of carvings (not necessarily Buddhist imagery, in fact) in order to reconstruct the often only partially preserved texts in terms of their content and translation to determine names and historical contexts as mentioned in these inscriptions, with some additional suggestions concerning the

\footnotetext{
${ }^{9}$ Relevant catalogue descriptions in: Bennmann and König (1994, 19-34), Fussman and BandiniKönig (1997, 58-72), Bandini-König (2003, 91-103; 2005, 95-104; 2011, 102-103; 2013, 269-301).

${ }^{10}$ Relevant catalogue descriptions in: Bennmann and Konig (1994, 35-142), Fussman and BandiniKönig (1997, 20-29); Bandini-König (2003, 103-172; 2005, 17-214; 2007, 19-251; 2009, 15-242; 2011, 21-257; 2013, 21-236).

${ }^{11}$ Relevant catalogue descriptions same as above: different genres are identified in the catalogue descriptions, but not ordered accordingly, except in: Fussman and Bandini-König (1997, 7-20, 30-57).

${ }^{12}$ Relevant catalogue descriptions same as above, except in: Fussman and bandini-König (1997, 36-53).

${ }^{13}$ Relevant catalogue descriptions same as above, except in: Fussman and Bandini-König 1997, 7-20, 29-30.
} 


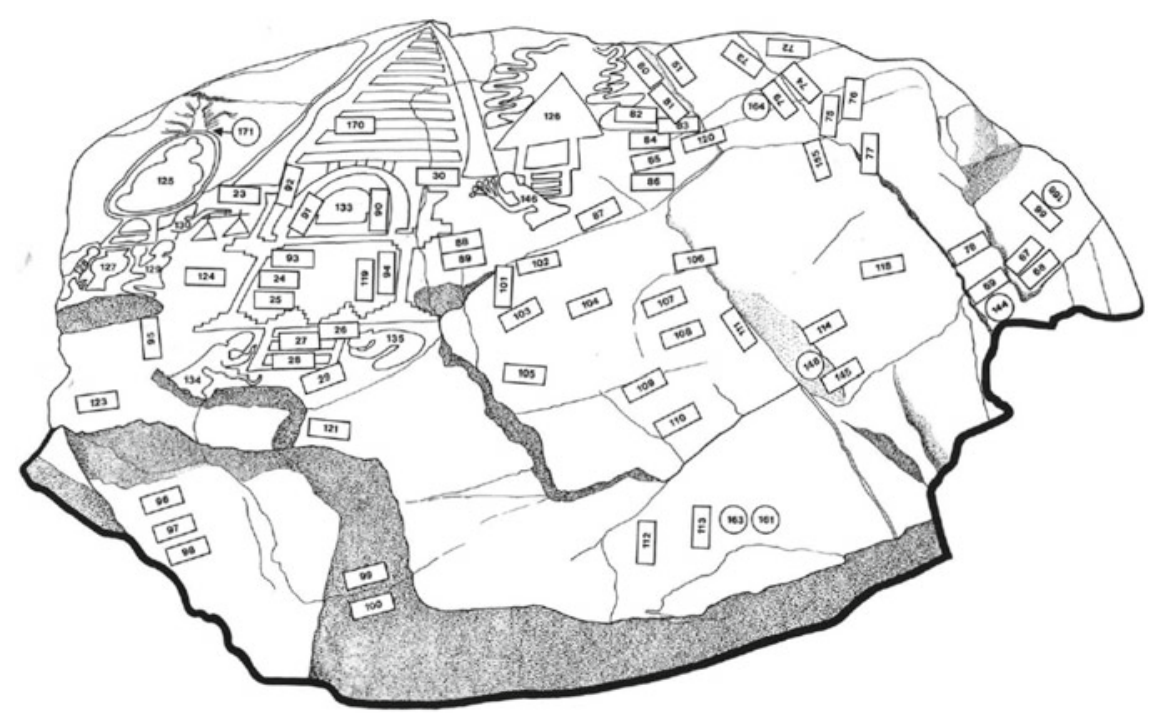

Fig. 20.2 Schematic of carvings (larger ones drawn and smaller ones rendered as circles) and inscriptions (squares) on the southwest side of the largest rock at the Shatial field station (stone 34; MANP vol. 2, Tafel D; Fussman and Bandini-König 1997)

travels of Buddhist monks and subsequent spread of Buddhist religious practice and scholarship to the East (Von Hinüber 1989a, b, 41-72, 73-106; Fussman 1993, 1-60; Fussman 1994, 57-72). As Jettmar puts forth in the first ANP volume from 1989, since their discovery in the early twentieth century up until the larger campaigns in the early 1980s, interpretative approaches to these data sets have been mainly ethnoarchaeological, namely, aiming to identify different and specific cultural and/or ethnic categories among the variety of carving types (Jettmar 1989, XXII). This approach was also pursued by Dani, who encountered considerable issues in his attempts to categorise the many different types of images of animals, human figures and indeterminable architectural structures that were discovered alongside more distinctly recognisable Buddhist imagery-images that were 'not easily included in classical iconography' (Dani 1983, 230-231; cf. Jettmar 1989). Especially the larger rocks tend to be covered with a great number of carvings and inscriptions, apparently scattered at random across the surface, which makes categorical determination of specific ethno-cultural groups virtually impossible (Fig. 20.2). Alternatively, this may simply indicate additions on the same rock from wide-ranging time periods (from prehistorical times up until medieval Silk Road passages, roughly), but such chronologies cannot be tested based on the rock's material properties or geological composition, as these have remained unchanged regardless of the addition of carvings throughout time (Jettmar 1989, XX).

Because of these issues, in his 1989 study Jettmar moved away from ethnoarchaeological interpretation that would directly imply a chronological distinction 
between Buddhist and non-Buddhist carvings; instead, his spatial-oriented approach considers the carvings as grouped together within bigger but still specific, contained mountain sites - for example, he suggests that there may have been a holy Buddhist site and festival tradition near the Thalpan field station to account for the many stupa carvings discovered there, but he also notes that this interpretation is speculative and not supported by textual sources or additional data (Jettmar 1989, XX-XXI). Other studies in this volume present detailed analyses of specific Karakorum carving types and interpretations of local contexts, thus providing an important basis for wider interpretative investigation ${ }^{14}$ - however, no substantial scholarly contributions from outside the Heidelberg and Gilgit project appear to have taken that next step as yet. The 1994-2007 Materialien zur Archaologie der Nordgebiete Pakistans (MANP) publications of the Oshibat, Shatial, and Thalpan field stations, supervised by Hauptmann as part of the Heidelberg Academy project, focus on providing a detailed documentation of the great diversity of carving types encountered, without necessarily attempting to identify specific categories or cultural groups as part of the documentation method. ${ }^{15}$

This thorough level of documentation is very helpful towards attempting a more interpretative overview, such as this paper aims to do concerning early Buddhist imagery encountered among the documented carvings. In the second ANP volume, Fussman presents an initial study that compares Karakorum carving from the Chilas field station depicting anthropomorphic figures of the Buddha to bronze Buddha figurines found in the Kashmiri mountain valleys in the Karakorum range, as well as to content from the Sanskrit Hatun inscription in the Ishkoman valley near GilgitBaltistan (and recognises several coinciding motifs in the description and depiction of the Buddha, respectively; Fussman 1993, 1-60). In the third ANP volume, Fussman focuses on hypothetical carving methods used by the craftsmen and carvers that created the more elaborate Buddhist carvings in the Chilas-Thalpan region, suggesting the use of predetermined sketches, diagrams, and decorative patterns that were meticulously applied to these carvings to make sure they adhered to Buddhist style and iconography, such as encountered traditionally in the earliest-known Buddhist material culture of Gandhara, as well as being still recognisable in later-dated Buddhist art and architecture encountered at Tibetan holy sites (Fussman 1994, 57-72). His focus remains on the style and execution of the Karakorum carvings, however, and does not raise further questions regarding the possible spread and/or technical criteria of Buddhist art and architecture beyond the Karakorum region, or indeed the possible significance of Gandhara in these material culture connections. Also in the third ANP volume, Monique Maillard and Robert Jera-Bezard present a brief study that compares the style and iconography of Chilas-Thalpan stupa carvings

\footnotetext{
${ }^{14}$ Including additional studies on Chinese epigraphy, different animal species recorded in the rock carvings, and linguistic interpretations/translations: Jettmar (1989, 1993); Fussman and Jettmar (1994).

${ }^{15}$ Apart from MANP Vol. 2 (Felsbildstation Shatial, Fussman and Bandini-König 1997), which does categorize its documentation according different carving types, the other MANP catalogues offer a full overview of stones with lists of carvings as they were encountered, thus without separating categories or applying further interpretations.
} 
to early stupa architecture and miniatures known from various Gandhara sites and museums, including Swat and Peshawar, and early Buddhist wall paintings from Xinjiang (Maillard and Jera-Bezard 1994, 173-200). Here, too, the focus remains on the detailed documentation of individual objects, providing a good basis for further study; but also this premise has so far hardly been taken on board by subsequent scholarship. ${ }^{16}$

The next section provides an analysis of the presently investigated data from the Thalpan, Oshibat and Shatial field stations. First, the data are presented in tables and distribution graphs. The first part of analysis considers the occurrence and appearance of the documented Buddhist carvings in detail and in the context of Gandharan archaeology (3.1). Next, the distribution of the documented carvings are analysed in the context of the Karakorum routes in terms of related environmental factors and connections with the wider region (3.2).

\subsection{Karakorum Data: The Thalpan, Oshibat and Shatial Field Stations}

The MANP documentation of the Thalpan-Chilas, Thalpan external, Shatial, and Oshibat field stations provide numbers of the stones studied, but not the number of individual carvings encountered (many stones contain multiple and often very diverse types of carvings); as a result, the total number of Karakorum carvings documented at this point remains by necessity an estimate. For the purpose of this study, the exact number of stones investigated has been taken as basic premise, and only the exact number of individual Buddhist carvings in the available documentation has been counted (hence, the individual carvings containing prehistoric, nomadic, animalistic or other types remain at this point uncounted). The statistical data pertaining the stones and exact number of carvings in question are represented in the tables and diagrams below. For the practical purpose of my initial analysis only (i.e. not intended as interpretative guideline), the types of Buddhist carvings in the data set have here been divided into (1) Buddha figures, (2) stupas, (3) worshippers, and the sub-division representing (4) combinations of Buddha figures and stupas. Further descriptions, analysis, and interpretation of the data follow after the graph (Fig. 20.3).

\footnotetext{
${ }^{16}$ Two follow-up studies are an article on stupa architecture by Bruneau (2007, 63-75) and a 2008 publication by Volker Thewalt, which presents a selected catalogue of notable stupa and related Buddhist architecture depicted in the Chilas and Oshibat field stations, offering detailed descriptions but no further interpretative overview or analyses of any wider contextual implications of the data listed (Thewalt 2008).
} 


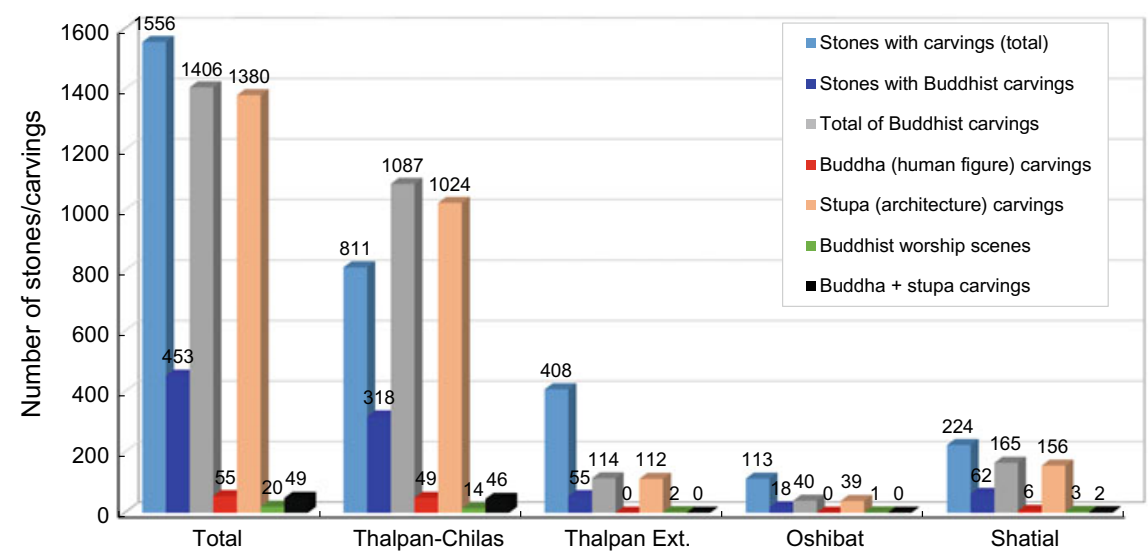

Fig. 20.3 Distribution of stones and Buddhist carvings in the Thalpan, Oshibat and Shatial data (Data based on MANP Vol. 1, 2, 6-11, documenting the Oshibat, Shatial, Thalpan-Chilas, Thalpanexternal field stations: Bennmann and König 1994; Fussman and Bandini-König 1997; BandiniKönig 2003, 2005, 2007, 2009, 2011, 2013)

\subsubsection{Analysis and Interpretation: Early Buddhist Carvings}

The following interpretation is based on these preliminary analyses only and is therefore intended to form an initial basis for future and more expanded studies concerning the Buddhist iconography and carving distribution of the Karakorum dataset. This initial step is particularly relevant as studies of the rise and spread of Buddhist material culture in and from the ancient Gandhara region, especially concerning the earliest anthropomorphic depictions of the Buddha in sculpture, have rarely incorporated interpretative analyses of imagery from Karakorum rock carvings. ${ }^{17}$ Moreover, most comments on these Buddhist rock carvings tend to single out (the often visually striking) anthropomorphic figures of the Buddha and provide individual case studies and comparisons (Maillard and Jera-Bezard 1994, 173-200; Bhattacharya 1977; Dani 1983; Fussman 1993, 1-60). However, based on the datasets from the Thalpan, Oshibat and Shatial field stations, the number of anthropomorphic depictions of the Buddha is substantially lower than the number of carvings depicting stupa monuments. Many of these carvings seem scattered among the rocks at random sequences and can be as small as $2 \times 4 \mathrm{~cm}$; on the other hand, especially at the Thalpan-Chilas and Shatial areas, we also find a stupa carvings as large as $130 \times$ $235 \mathrm{~cm}$ (MANP Band 1, 2: Bennmann and König 1994; Fussman and Bandini-König

\footnotetext{
${ }^{17}$ The significance of the carvings is indeed discussed in e.g., Carter (1993), Hauptmann (2008), Neelis (2011), but not as part of comprehensive interpretative or distribution studies as yet. Additionally, the Karakorum carvings have not been used for in-depth comparative studies with Buddhist carvings from e.g. Swat Valley and Hindu Kush, which would certainly present material for future research for which these initial steps will present an important basis (cf. Olivieri 2013, on SwatMalakand carvings, and Kotera et al. 1971 on Hindu Kush carvings).
} 

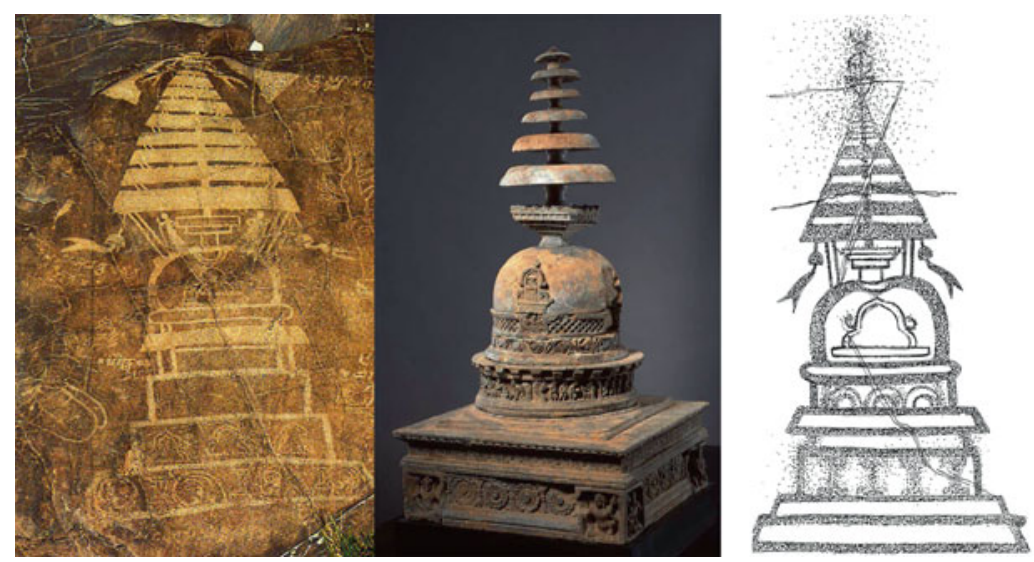

Fig. 20.4 Comparison of stupa architecture. Left: Thalpan-Chilas, stone 30:1, Tafel III a (BandiniKönig 2003). Centre: schist reliquary stupa (centre), $83 \mathrm{~cm}$ height, from Gandhara, possibly Taxila, 1st-2nd century CE (Carlton Rochell Asian Art Gallery, private collection, New York). Right: Thalpan-Chilas, schematic of stone 41:3, Tafel 25 (Bandini-König 2003)

1997; and Band 6, 7: Bandini-König 2003, 2005). The amount of architectural detail of especially these larger carvings is noteworthy: Maillard and Jera-Bezard make comparisons with motifs and depictions of stupa architecture excavated at Gandhara sites in Swat and Peshawar as well as with the famous Buddhist wall paintings at Dunhuang (Maillard and Jera-Bezard 1994, 176-181). In fact, most comparisons consider architecture and imagery from the 3rd-4th century CE onwards; however, when we look at some of the earliest-known stupa architecture from Gandhara (i.e., Sirkap, Taxila), the direct parallels are no less striking (see Fig. 20.4; cf. Van Aerde 2018, 203-229).

Chronology for the Karakorum carvings tends to rely on stylistic features as well as surrounding epigraphical carvings that generally focus on such later periods; but the actual features of the depicted stupas in these data sets in fact suggest a chronology for Buddhist carvings from as early as the late 1 st century BCE-early 1 st century CE onwards. Possible parallels of stupa architecture depictions in rock carving from the Western Hindu Kush mountains (the region of Afghanistan generally referred to as Bactria in the antiquity) were discovered by a Japanese campaign in the 1970s, but they do not currently survive in situ; however, the surviving documentation of these carvings depict stupas that directly resemble those encountered in the Karakorum carvings at the Thalpan and Shatial stations (see Fig. 20.5), which likewise hints at a presence of Buddhist imagery in rock carvings in the mountain ranges surrounding Gandhara from the Bactrian and early Kushan eras onwards from ca. late 1st century BCE-early 1st century CE (Kotera et al. 1971, 40, Fig. 38; cf. Klimburg-Salter 1989, 150).

Due to this unfortunate lack of documentation from the Hindu Kush range, there is a danger that more prominent attention for the better-documented Karakorum 

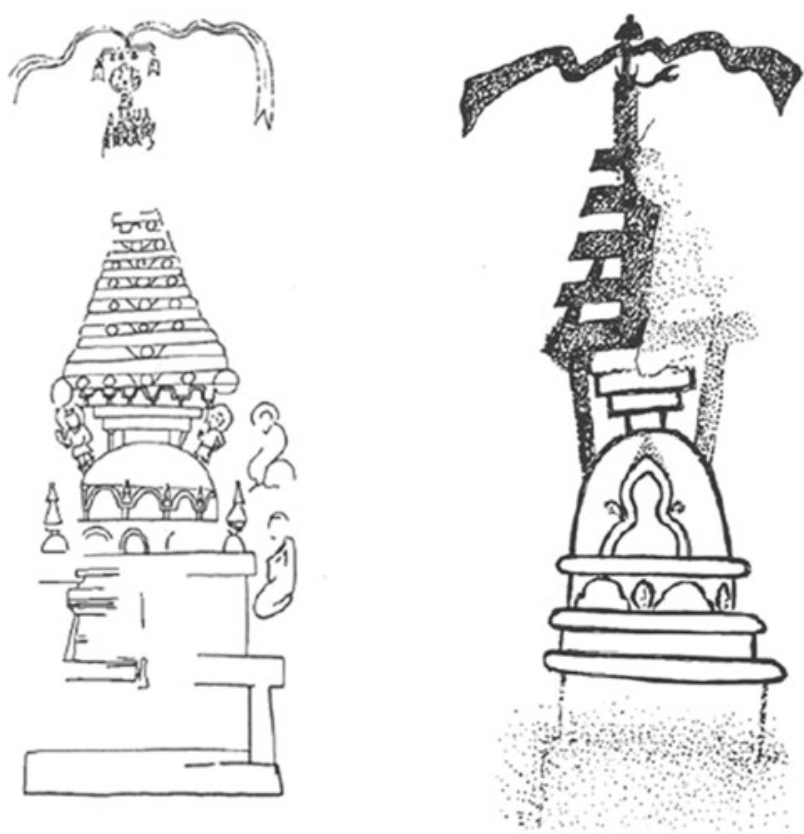

Fig. 20.5 Left: schematic of stupa carving at Bamiyan, western Hindu Kush, Afghanistan (Kotera et al. 1971, Fig. 38, pp. 40). Right: Schematic of stupa carving at Shatial field station, Karakorum, Pakistan (stone 164:7, Tafel 28, Fussman and Bandini-König 1997)

carvings would lead to an unbalanced interpretation of carving distributions (and subsequent mountain route reconstructions in the region) in favour of the eastern mountain ranges. Yet, while keeping in mind that at least hypothetically we should include the western Hindu Kush range in wider considerations of Gandhara's connectedness, it is equally important to focus in-depth on the Karakorum data sets now, as they seem likely to be the only available data at least in the foreseeable future.

One of the most important points that emerges from the Karakorum data, is the fact that the documented Buddha figures do not appear to be individual depictions of certain Buddhist scenes -the examples from this dataset, to be precise, appear to perhaps depict anthropomorphic sculptures of the Buddha, including statue bases and architectural contexts; to be more exact, nearly all images of the Buddha from the Thalpan, Shatial and Oshibat stations are images of Buddhist sculptures that were part of or position directly besides stupa architecture. This would mean that comparisons between these carvings and actual stupa architecture (indeed mainly from Gandhara) are much more correct in perspective than comparisons with wall paintings that visualise Buddhist narrative scenes (such as known from Xinjiang caves). Regrettably, most Buddhist sculptures and reliefs from Gandhara sites were removed upon excavation in the 19th and early 20th century, but some excavation reports still allow us to reconstruct larger monuments at least in part, and in some (but 
(a)

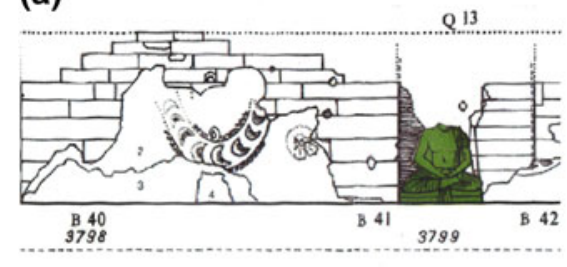

(b)

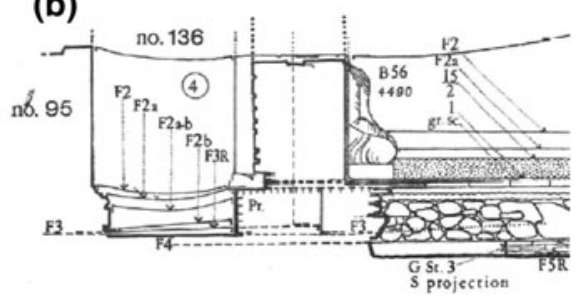

Fig. 20.6 Schematics of in situ Buddhist sculptural elements of stupa architecture at Butkara I, Gandhara, as documented by Domenico Faccenna and the IsMEO team in 1956 (Faccenna 1980, Plates XIV and XXXVI)

not many) cases sculptural elements of the architecture have been documented in situ, before they were removed, for example in the excavation reports of the Butkara I site (see Fig. 20.6), which represents the find spots of Buddha sculptures that have been interpreted as sculptures re-used in architectural stupa context (A) and as originally part of the architectural stupa context (B). ${ }^{18}$

Also smaller, reliquary stupa sculptures recovered from these same sites (as seen in Fig. 20.4) provide valuable comparative sources. Even when sculptures that are now taken out of their original contexts are considered, the visual similarities are directly noteworthy: in fact, the details of the execution and style of the anthropomorphic depictions, posturing, attributes and clothing of the Buddha carvings from the Karakorum data sets correspond acutely with those of sculptures recovered from relatively early Gandharan Buddhist sites, such as Butkara and Taxila (Fig. 20.7).

Later-dated Buddhist figures, generally dated to Gupta and Xinjiang origins, are distinctly different in visual detail; the earlier Gandhara Buddhas are less elaborate in terms of their amount and style of attributes, and posturing, and they tend to feature a distinct style of rendering clothing with many folds (previously regarded as a distinct criterion of 'Greco-Buddhist' art because of parallels with robed Hellenistic sculptures), as well as an apparently characteristic rendering of serene facial features and reflective expression (previously likewise regarded as example of a 'Greek' artistic filter) that in fact corresponds with early descriptions of the Buddha's features as known from the Jataka tales, among other early Buddhist textual sources (see further Van Aerde 2018, 203-229). All these characteristics are recognisable in the Buddha carvings from the Thalpan, Oshibat and Shatial datasets-which would indicate another argument for a relatively earlier commence of these Buddhist carvings' chronology in these mountains. Moreover, it would be a particularly clear indication that these carvings were indeed depictions of sculptures of the Buddha, rather than images depicting the Buddha's life as in wall paintings. Even the few apparently individual Buddha figures in the data set show such direct resemblance to

\footnotetext{
${ }^{18}$ Faccenna (1980, Vol. 1-5) provide a thorough documentation of early Gandharan stupa architecture, including in situ anthropomorphic Buddhist sculptural elements. See also descriptions in: Marshall (1975) (concerning Sirkap, Taxila) and Faccenna and Taddei 1993 (concerning Swat valley).
} 


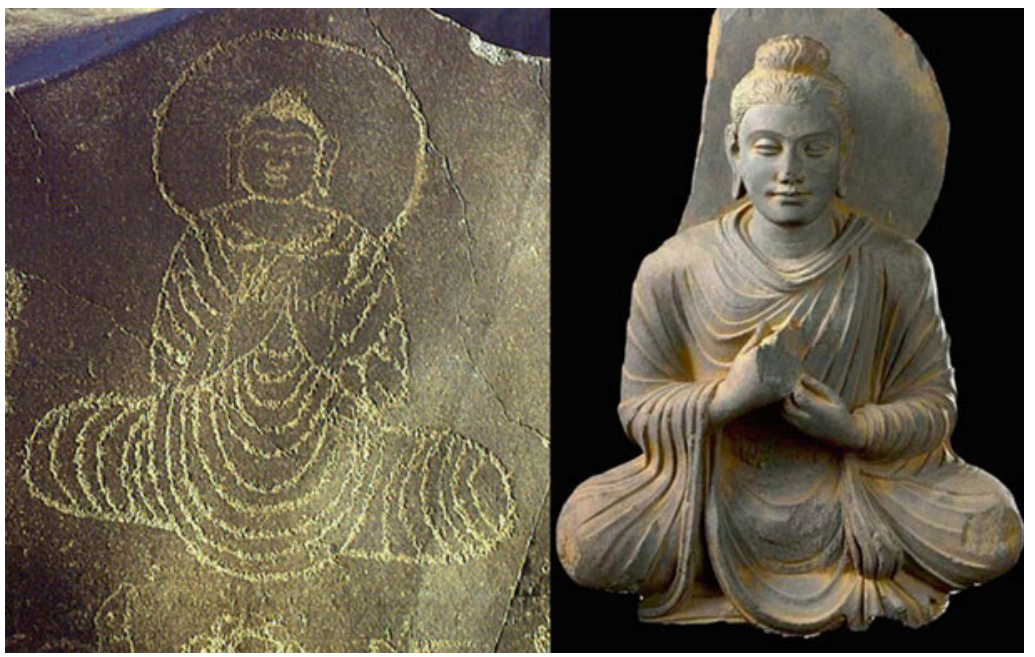

Fig. 20.7 Left: rock carving of seated Buddha at Thalpan-Chilas (stone 195:65, Tafel 3, BandiniKönig 2005). Right: sculpture of seated Buddha, Swat Valley, Gandhara (Lahore Museum, Cat. Nr. 572). Note esp. the similarities in posture, positioning of hands, facial features (rendering of eyebrows, urna dot, earlobes, topknot), the long robe with many folds, and halo

Gandharan Buddha sculptures (as shown in Fig. 20.6), that they, too, are arguably depictions of sculptures rather than human figures; in addition, the presence of kneeling worshippers surrounding these individual (and notably larger-than-life) Buddhas, which are directly comparable with the worshipper figures found surrounded many stupa carvings in the same data set, seems to indicate that these carvings indeed represented sculptures, i.e., stone monuments meant for worship and as incentive to meditation in the same way as stupas functioned. ${ }^{19}$

In sum, Buddhist imagery as found among the Karakorum carvings are (1) predominantly depictions of stupa architecture; (2) the far majority of anthropomorphic Buddha figures in the data set are directly related to stupas, i.e. representations of sculptures that were part of stupa architecture; (3) in execution and style, these Buddhas are directly comparable with the earliest-known anthropomorphic depictures of the Buddha from Gandharan sites. This suggests an actual 'missing link' between Gandhara and the rise of Chinese Buddhism in Xinjiang, with the Karakorum mountains as linking passageways (Maillard and Jera-Bezard 1994). But an important nuance is required here: by looking closer at the carvings, namely, by recognising them as carvings of architecture and sculptures rather than as merely Buddhist imagery, the question of their functionality becomes crucial. To explore this further, we need to look closer at possible distribution patterns as found within these original mountain environments.

\footnotetext{
${ }^{19}$ No full interpretative study has so far been done on the presence of worshippers in Buddhist carvings (some brief mentions are made in: Fussmann 1994; Maillaird and Jera-Bezard 1994).
} 


\subsubsection{Discussion: Distribution of Carvings in the Karakorum Mountains}

When considering the documented data, as presented in Fig. 20.3, the main point of interest seems the fact that stupas are the most numerous type of Buddhist carving encountered by far; these data sets contain over a thousand stupas, but only fifty-five recorded anthropomorphic images of the Buddha. Depictions of Buddha are relatively rare in the dataset - though it is noteworthy that the recorded Buddhas in the data set tend to larger in size than the majority of recorded stupa carvings (the average for stupas is around $30-40 \mathrm{~cm}$ in height, with the exceptions being often triple in size but much fewer in number, whereas the average for Buddha carvings appears to be around $70-80 \mathrm{~cm}$ in height). Another noteworthy aspect is the fact that relatively few stones among the total documented stones feature Buddhist carvings, whereas the number of individual Buddhist carvings is much higher, respectively. However, most Buddhist carvings have been found grouped on single stones; i.e., multiple carvings appearing on the same stone, which are generally also the larger stones documented at the relevant field stations. ${ }^{20}$ Another point of interest here is the fact that 49 out of the 55 documented Buddhas are clearly part of stupa carvings or placed in their direct vicinity, and all these combinations seem to feature surrounding carvings of worshippers, too. This would again confirm that these anthropomorphic Buddhas were indeed depictions of sculptures (either free-standing statues such as found at Gandhara Buddhist sanctuaries or architecturally incorporated into the stupa structures), as suggested in the section above, and not Buddhist narrative scenes that would be more comparable to wall paintings. Their role as part of stupa depictions seems indeed important for understanding their functionality; it would explain, for one, why the recorded Buddhist images were carved together on a fewer number of specific stones, and most likely with additions and alterations added over time on these same stones. In other words, these carvings should not be regarded as separate images, but as components of what appear to have been visualisations in the rock of physical stupa monuments, many of them very similar to those known from early Buddhist sites in Gandhara. As such, the function of these Buddhist carving groups may not have been so different from the function of Gandhara stupa architecture, if indeed at all. As visual monuments for worship and reflection, according to early Buddhist practices, these carving groups will have been much more effective in a recognisable group upon certain recognisable stones along the routes taken by Karakorum travellers, as opposed to having them scattered around on multiple rocks across the area. Moreover, the particular resemblance to early Buddhist architecture and sculpture from Gandhara does not necessarily imply that these carvings need all be of a relatively early dating; especially the larger and most detailed stupas and Buddhas are carved deeply in the rocks, which may indicate that the carvings were initiated in those early times, roughly around the early 1 st century $\mathrm{CE}$, and that the carvings were elaborated, deepened, even intentionally maintained (as a physical stupa

\footnotetext{
${ }^{20}$ Especially Fussman and Bandini-König (1997) and Bandini-König (2003, 2005) offer for documentation and reconstruction drawings of such large stones and carving groups.
} 
monument would be) throughout the passage of time as part of worship by Buddhist practitioners that continued to pass them in the mountains ranges-perhaps as part of intentionally religious caravans, maybe simply as merchant travellers seeking to practice their religion along their trade routes through these mountains. ${ }^{21}$ This brings in mind Fussmanns suggestion that the larger stupas were carved according to specific (most likely Gandharan) templates; but perhaps this is only true for the original layer of their carvings, which indeed is so directly comparable to Gandharan stupas and Buddhas that it would suggest the hand of certain craftsmen with knowledge of these sculptures and architecture. However, these carvings may subsequently have been maintained throughout many subsequent centuries by passing caravans instead, for example, by means of deepening the existing carvings, and perhaps also altered and expanded with worshipping figures and animal figures, of which most appear less directly recognisable in style and execution.

It also brings to mind Jettmar's suggestion of a possible Buddhist sanctuary at the Thalpan location; the spike in numbers of stupas and related Buddha depictions in the Thalpan-Chilas data sets would seem to support this option (Jettmar 1993, XX-XXI). Hauptmann has also noted that 5th-century Chinese pilgrims mentioned travelling to Buddhist sanctuaries near a specific 'trade emporium' they refer to as 'Talilo', and suggests this may have referenced Thalpan-especially since this part of the Karakorum Indus indeed appears to have functioned as passage to and from prominent Gandharan cities such as Taxila (by then under Kushan administration), the Kashmir valley, and ultimately Xinjiang in the east, with the number and scope of traffic roads with checkpoints and possibly even forts continuously expanding along these routes throughout the first five centuries CE (Hauptmann 2009, 8-9). However, there are no currently known archaeological or textual sources that would support the former presence of such a larger Buddhist sanctuary (which would have included architecture and physical monuments, according to the above-mentioned Chinese sources) at the Thalpan area, or indeed remains of a large-scale trade emporium. ${ }^{22}$ This current lack of evidence might have been solved by more extensive excavations in the area, but especially due to the building of the Diamer-Basha dam, this does no longer seem feasible in the near future. Yet, hypothetically, the mere possibility of a physical 'Gandharan-type' early Buddhist sanctuary outside of Gandhara is something that traditional Gandharan scholarship never considered and therefore never looked for-but it is also something that the distinct presence, execution, and detailed style of the Karakorum stupa and Buddha rock carvings in this area certainly seem to make more plausible to at least consider.

\footnotetext{
${ }^{21}$ As initially noted by Fussmann (1994), and subsequently also remarked upon by Neelis (2014a, b, 45-64). This would be an interesting and possibly important topic for future research.

${ }^{22} \mathrm{~A}$ trade post or traffic station may have been built out of wood and other less durable material (e.g., textiles), but objects such as coins, pottery etc. may be expected to remain. It is also a reasonable deduction that such a Buddhist sanctuary would have featured more than only rock carvings. Excavations near the Diamer-dam site may have given more insight into this, but they have now become impossible. Apart from gathering more as yet undocumented carvings throughout the region, other excavations projects may have given us more indications of this sanctuary hypothesis; unfortunately, also such plans do not seem feasible in the near future.
} 


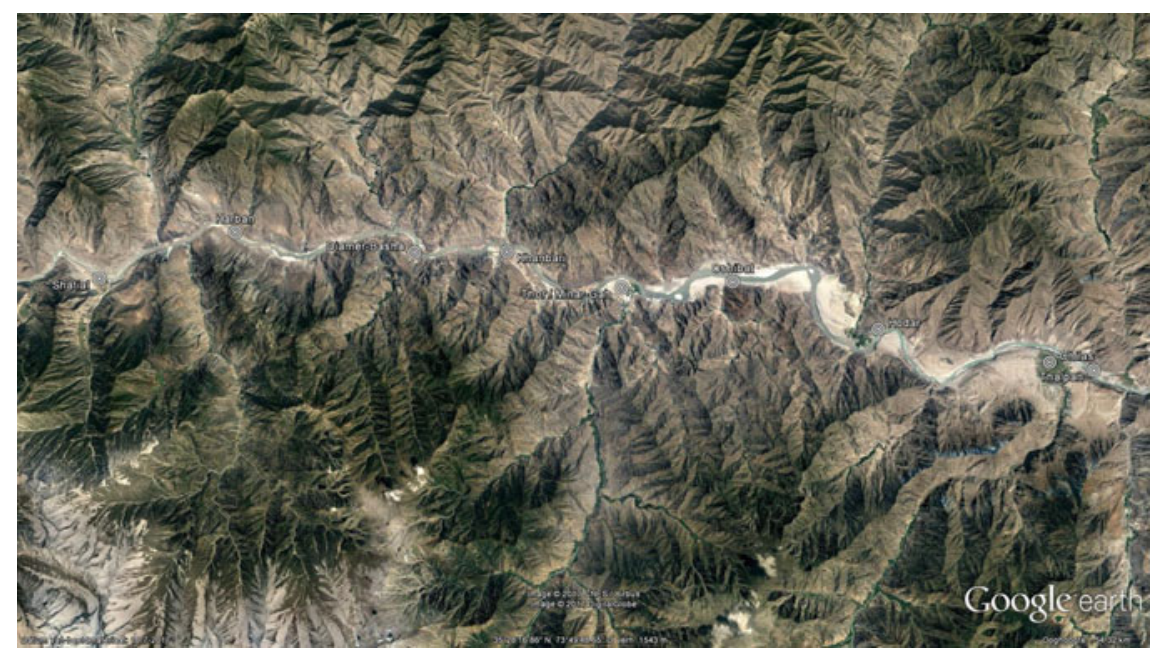

Fig. 20.8 Recent satellite image of the area between Shatial (west) and Thalpan-Chilas (east), along the flow of the Indus. All main field stations where rock carvings have been discovered between 1979 and 2013 have been marked: Shatial, Harban, Diamer-Basha, Khanbari, Thor, Minar-Gah, Oshibat, Hodar, Chilas and Thalpan (GoogleEarth 2017)

On the other hand, it is no less important to closely consider the natural environment of the relevant valley in our interpretations and hypotheses. ${ }^{23}$ When we return to the documented data, we can in fact observe an increase in the number of stupas documented at the Shatial field station that is quite similar to the increase noted at Thalpan-Chilas; that is, the number of recorded stones with Buddhist carvings outside the Thalpan banks is relatively smaller overall, yet the similar pattern (i.e., the spike in stupas) is still noteworthy, especially in context with the data from Oshibat, which is in fact much closer in vicinity to Thalpan than Shatial (see Fig. 20.8). ${ }^{24}$

Other than the still unsupported hypothesis of a physical Buddhist sanctuary, these stupa spikes at Shatial and Thalpan may instead, or at least also be connected to the fact that both locations are near remarkably sharp bends in the Indus (namely, flowing southwards from Shatial, down towards the slopes of Gandhara, and northwards from Thalpan, up towards the Gilgit-Baltistan region). These specific locations may have indicated more important stations along the route, marking the significant bends they announced; perhaps they functioned as notable road stations where mountain

\footnotetext{
${ }^{23}$ Similar hypotheses concerning waystations have already been advanced by Stein (1944), Jettmar (1985). In addition, possible parallels could be sought with data from the Hindu Kush mountain range for future research (cf. Neelis 2014a, b, 3-17).

${ }^{24}$ The Heidelberg Academy team charted several more clusters of carvings (but not all currently available in MANP) along the Indus riverbanks in the valley passage reaching from Shatial in the west to Thalpan in the east, but so far these do not appear to have been as numerous in terms of specific Buddhist carvings nor do they seem to have been grouped together like at Thalpan or, in lesser degree, Shatial.
} 
caravans could stay overnight, hence allowing travellers more time for worship and reflection such as the stupa and Buddha carvings appear to have accommodates-perhaps, indeed, that may have been their original functionality, to accommodate the needs of those passing by the more important road stations. And as a result, with the increasing centuries and the similar increase in Buddhist followers in the region, these initial carved early Buddhist, 'Gandharan' stupas may indeed have developed into larger-scale religious sanctuaries known as far as midland China, in the same way as that the road stations may have developed into emporia that became known across the region. This is of course directly relevant for challenging the compartmentalised tendencies of Gandharan Buddhist archaeology, in proving the opposite. As it is, the archaeological and textual sources available at this point seem only to support these early Buddhist origins of the carvings as well as their apparent connection with the structure of the natural environment of the Karakorum Indus; in specific, the river's flow and bends along the mountain valleys and the way the travellers' route appeared to have followed it. Therefore, concerning the tradition division between cultural and environmental approaches, this indeed suggests the necessity of an interdisciplinary bridge between the two.

While hypothetical reconstructions of sanctuaries along the river are difficult from an archaeological perspective at this point, reconstructions of the route itself are more feasible, especially when taking the environment as part of the consideration. This is where the approach of archaeological data as variables comes into play more concretely and can indeed become a tool to work with; the consideration of (complex and hence unpredictable) variables instead of predetermined categories simply does not allows for a separation of archaeological, contextual, environmental, textual sources, etc. On the contrary, all these aspects are variables of both the physical region and the wider process of connections and interactions under examination here. Even when some variables by necessity remain hypothetical (such as the possibility of a larger sanctuary at Thalpan), the incentive for that hypothesis (i.e., the notable spike in stupa carvings recorded) is yet another variable in itself, which in turn appears closely connected, indeed even a result of the structure of the surrounding natural environment (i.e., the fact that Thalpan was located at one of the most major bends of the Karakorum Indus). In effect, none of these aspects and/or data can nor should be studied in separation. Similarly, the direct similarities in style and execution of the depicted stupas and Buddha sculptures in the studied data sets should not merely be 'singled out' as a topic of study, thus suggesting a linear line of cause and effect; instead, when we consider the Gandharan origins of these carvings are yet another variable in a dynamic process of interregional interactions, it becomes clear that we cannot denominate a single 'function' or 'intention' to them, as such. Whereas these early Buddhist carvings may have originally been intended as opportunities for worship for travellers passing through the mountains, they appear to have also come to function as landmarks at certain prominent changes in the environment and help travellers navigate their routes, and as a result these Buddhist images were spread not only alongside a more deliberately religious expansion of early Buddhism from Gandhara to the east (such as traditionally derived from textual sources) but also as additional incentive to as well as constituent of that ever-expanding process. 
In other words, the appearance and subsequent increase in early Buddhist imagery along the Karakorum routes, especially when we keep in mind above-mentioned comparisons in style and content with both early Gandhara sites and the earliest Buddhist depictions in Xinjiang and Gansu, appears to have been a dynamic and distinctly non-linear variable in what is still mainly considered a linear line of causeand-effect: Buddhism being carried to China. Whereas the original intention of the earliest Karakorum stupa carvings may have simply been to offer Buddhist travellers a place for worship along their passage, the unintended effect of these carvings seems to have been to increasingly raise awareness of and interest in Buddhism in regions east of Gandhara-moreover, the possible presence of larger, famous Buddhist sanctuaries at these same landmarks along the Karakorum route in the 5th century will have been another originally unintended result of that same dynamic and ongoing process. Such non-linear variables can only be charted in hypothetical (phase space) models, as mentioned in the introduction; however, the consideration of these variables, as opposed to a compartmentalised approach, also allows us to hypothetically chart the physical route(s) in more detail.

One of the main variables involved here is one that appears relatively fixed, or at least logically deducible: namely, the fact that the distribution of rock carvings follows the flow of the Indus River. The convenience, even necessity of proximity to water while traversing these mountains, combined with the lower, more accessible grounds of the river valleys, would make the river's flow the most sensible route to follow for any travellers, either in larger caravans or not. As far as these data sets have recorded, no rock carvings have been discovered higher up the surrounding mountain slopes, which also suggest an absence of travellers there (again the most sensible, practical option). The structure of the natural environment is the most determining variable in this case, directly affecting people's choices for the routes they travelled - and in consequence likewise affecting their choices of where to carve their stupas along the way (for hypothetical route, see Fig. 20.9).

Ideally, the next step would now be to document more data from along the Karakorum Indus. Up until recently, explorations and studies have been conducted up until the Gilgit and Gilgit-Baltistan areas, in a northern upwards direction from the Thalpan field stations; unfortunately, no catalogues or very thorough documentation of carvings have yet been possible. Earlier this year, German scholars Horst Geerken and Annette Bräker published a memoir of their travels around the Gilgit area up until 1998, featuring several photographs and reports of rock carvings that very strongly resemble those so far documented by MANP, including early Buddhist stupa imagery (see Fig. 20.10a), but also carvings that more closely resemble Buddhist depictions from Chinese paintings of the much later Tang Dynasty, 618-907 CE (Fig. 20.9b; Geerken and Bräker 2017, 224-225).

The latter presents yet another possible argument for the increasing role that Buddhist carvings and perhaps indeed sanctuaries came to play along these mountain routes since the first appearance of early carvings of Gandharan-type stupas; it is noteworthy, too, that most if not all Buddhist depictions as now documented in the lower Indus Karakorum valleys, from Shatial to Thapan, directly resemble much earlier Buddhist depictions from Gandhara. For example, if a famous Buddhist sanctuary near Thalpan was known by the 5th century, perhaps such later styles would 


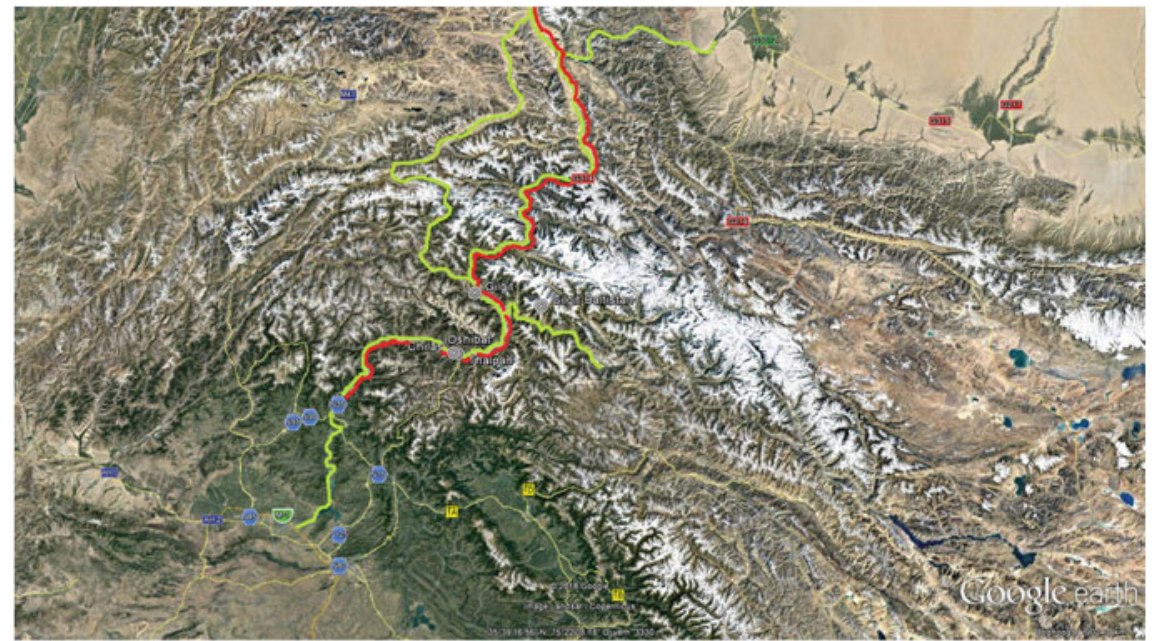

\footnotetext{
- Hypothescal ancient rouse (trom Gandhara to Taklamakan Deser, following the hdus River)

- Karakorum Highway (modern rouke, N35 in Pakistan and G314 in China)

(20) Main stes (current stuation)
}

Satelite botage: GoogleEarth 2018

Fig. 20.9 Hypothetical ancient route through the Karakorum mountain range (GoogleEarth 2017)

(a)

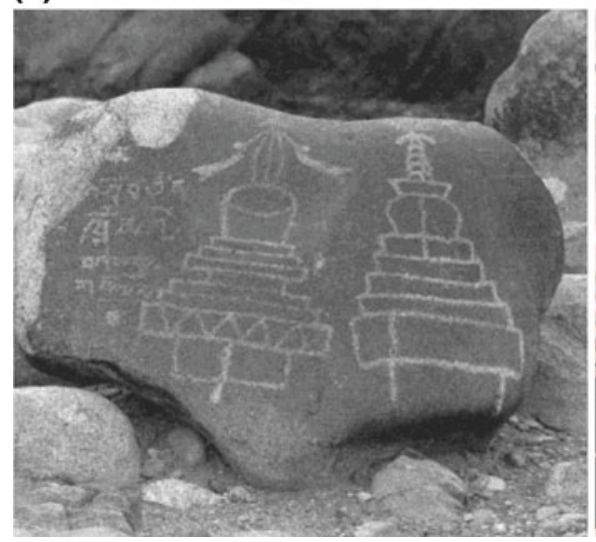

(b)

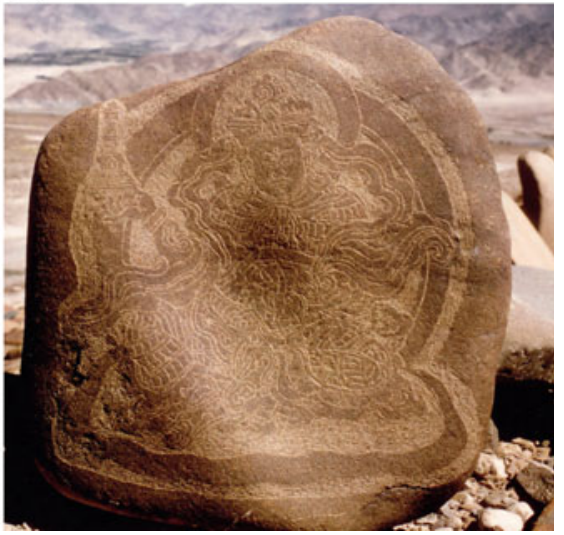

Fig. 20.10 a Stupa rock carvings recorded near Gilgit (Geerken and Bräker 2017, Ill. 132, pp. 225). b Buddha rock carving near Gilgit, (Geerken and Bräker 2017, Ill. 33.2, pp. 48)

also be expected here. This may be an indication that such a sanctuary may be sought closer to Gilgit, and the upper flow of the Indus, after all. In either case, it does show a continuation of Buddhist carvings along this river-guided route. And hypothetically, if the above-mentioned variables are likewise considered for the as yet undocumented ranges of the mountains (i.e., accessibility of the natural environment, continuation of human presence and passage, religious needs of Buddhist travellers), we can plot 
the most likely routes that would from as early as the late 1st century BCE onwards to have been actively traversed arteries allowing travellers and trade caravans back and forth through these mountains. As such, these routes physically allowed access from the Gandhara region in the west to the Xinjiang region of China in the east, and vice versa, thus connecting important nodes in the increasingly expanding Silk Roads networks, especially following the Han Dynasty's opening of the Jade Gate for trade across the Tarim Basin and the Kushan administration's expansion of trade networks in Gandhara in the 1st century BCE. And the Karakorum rock carvings, as recorded so far, provide us actual evidence of these important connections.

In order to achieve a more empirical reconstruction of these routes (building on the hypothesis proposed in Fig. 20.9), a continuing documentation of rock carvings is needed along the Karakorum Indus, going beyond the Gilgit region up until the first ranges of the Tarim Basin in the northeast. As reported by scholars and explorers alike who have visited these parts, a great number of carvings remain unrecorded and most likely many more still undiscovered across these parts; moreover, additional excavations would help reveal new archaeological data concerning the trade posts and sanctuaries that came to mark these important Silk Roads routes. But as mentioned above, due to increasing issues in the region at present, mainly dam constructions and political unrest, such campaigns seem unlikely to be possible in the near future. An additional, but no less worrying factor is the effect of climate change in these mountains; recent data predicts such a significant rise of temperatures in the Himalayas, including the upper plateaus of the Hindu Kush and Karakorum ranges, that many glaciers are expected to melt within the next several decades (most recent data: Cogley 2017, 166-167). This is of course a primary concern for the water resources of Central Asia, but it is also a direct threat to any archaeological remains, including rocks carvings, in these regions, which will either be destroyed or made inaccessible due to excessive melt water and shifting glaciers. In addition to these problematic modern variables in the region, modern technology does allow different ways of access; satellite imagery and drones may become the best available tools to keep studying this region in the near future. For that reason, further in-depth analysis of the so-far documented data from the Karakorum Indus valleys is important for a variety of interdisciplinary studies, among which archaeology and environmental science.

\subsection{Conclusions}

This contribution explored the results of a preliminary interpretative study of this particular Karakorum rock carvings dataset, in order to form a basis for future research that uses these data within the wider frame of studying the dynamics of early Silk Roads networks. The results constitute the following main points.

(1) Concerning the functionality of the documented Buddhist carvings: the depictions in this dataset can be interpreted as visual representations of physical early Buddhist architecture and anthropomorphic sculpture that closely resemble architecture and sculpture encountered in Gandhara from the 1st century BCE onwards. As such, especially the numerous stupa carvings, may have 
functioned as religious monuments for travellers to enable their worship and meditation according to their Buddhist practices. This could subsequently raise further theoretical considerations concerning the meaning and/or intention of such religious monuments: namely, were they simply material monuments of religion, or should we regard them as material monuments that are simultaneously cases of 'lived religion'? ${ }^{25}$ In addition, multiple Buddhist carvings collected on certain large stones appear to have also functioned as landmarks along the main routes undertaken by travellers and caravans through these mountains, with apparent higher numbers appearing at notable changes in the flow of the Indus River along these routes.

(2) The data subsequently present insight into the direction of the routes through these mountains. Especially many stupa carvings followed the main route along the Indus river directly, even if their function as physical landmarks may have not been their initially intended function (as opposed to religious function for travellers); this connection to the natural environment, which determined the best mountain routes, allows us to hypothesise the continuation of these routes beyond the documented data that is currently available; namely, the stupa carvings can be considered important variables in the development of these trade routes between Gandhara and the Tarim Basin. Moreover, as a result of both their religious functionality and visibility as landmarks, these cravings may add evidence or at least arguments for the presence of larger Buddhist sanctuaries and trade emporia along these same routes over time (so far unexcavated).

(3) The dataset also provides insights concerning Gandhara itself-in terms of its early Buddhist archaeology as well as the wider connectedness of the region. The stupas and especially depictions of the Buddha closely resemble architecture and sculpture from early Buddhist Gandharan sites, such as Taxila and Butkara, in terms of style, execution/manufacture, attributes, and architectural features. This suggests not only that Buddhist carvings would have begun to appear in the Karakorum range from the late 1st century BCE onwards, but also provides evidence that Gandharan Buddhist material culture reached well beyond the Gandhara region already since its earliest appearance. The data so far suggest a process of connectedness: at the same time that the earliest anthropomorphic depictions of the Buddha become prominent in Gandhara, featuring certain Hellenistic features and sculpting techniques as variables contributing to that development, those images also became variables in the interregional exchange enabled by the increasingly dynamic traffic of the Silk Roads. This traffic and exchange became especially important in Gandhara from the 1st century BCE, with the opening of the Jade Gate by the Han Dynasty and subsequently by the Kushan focus on trade networks in and from Gandhara. Initial 19th-century Gandharan scholarship considered Gandharan Buddhist art as a unique (and inherently Hellenistic) category, and as such distinct from Buddhist art that developed in East Asia later. The Karakorum carvings strongly underline the fault in these traditional studies by means of empirical evidence, which supports

\footnotetext{
${ }^{25}$ An interesting parallel here may be recent studies of 'lived religion' concerning Ancient Roman religious monuments, such as presented by Jörg Rüpke (2016).
} 
the important trend of both Buddhist and Silk Roads scholarship moving beyond such predetermined interpretations.

(4) Subsequently, these data have implications for studies of the spread of Buddhism, as well. Unlike the focus of textual sources concerning missions by monks to spread the religion, we here find an at least simultaneous process of a seemingly non-intentional spread of Buddhist stupas from Gandhara throughout the Karakorum range, most likely all the way northeast to the Xinjiang and Gansu areas in Western China-where the subsequent earliest Buddhist imagery are known from the Duanhuang caves. The Karakorum carvings may present an empirical 'missing link' between the Gandhara and these Chinese sites. The most interesting feature here appears to be the unintentionality-namely, the fact that the Karakorum stupa carvings that would originally have been intended for practical use for Buddhist travellers may indeed have incited such an increased accessibility to Buddhist imagery and content that they subsequently also increased a wider interest in the religion, hence also increasing calls for Buddhist monks to travel east to fulfil these new religious interests. Rather than distinct or contradictory, these seem to have been simultaneous processes. An interesting example is put forth by Lars Fogelin in his recent overview of Buddhist archaeology throughout the Indian peninsula, demonstrating that the archaeological data frequently paint a picture of reality that notably defers from historical narratives that are based on textual sources. ${ }^{26}$ When stepping away from fixed compartmentalised perspectives, such contradictions instead seem to indicate the occurrence of dynamic processes that did not necessarily exclude one another at all, but coexisted and indeed influenced each other in flexible and unpredictable (at least often unintentional) ways. This, in turn, may indicate a certain level of 'agency' of early Buddhist imagery, in the sense that their effect seems to go well beyond the original intentions with which they were created. This, too, would be interesting to pursue in future research. This contribution's exploration of how multiple variables continuously influenced the functionality, subsequent effects (intended and unintended), and developments of the Karakorum Buddhist carvings is merely one example of dynamic interactions that happened along and were made possible because of these mountain routes.

Whereas preconceived concepts and categories have often 'proven useful in ordering things', to return to the words of Albert Einstein, we should be wary of tendencies to compartmentalise, as that can truly make 'the path of scientific progress impassable' (Einstein 1916; see note 2). As this preliminary study of Buddhist carvings

\footnotetext{
${ }^{26}$ One interesting example of this pertaining specifically to the interpretation of archaeological data, is Fogelin's presentation of a case where textual sources have suggested the rise of early Buddhist monasteries as much later than the tradition of ascetic, travelling monks, whereas the archaeological evidence points at a much earlier rise of monasteries that would have coincided with the ascetic traditions (it appears that the contemporary texts and scriptures highlighted the importance of ascetics because of a scholarly and religious interest in the tradition, which subsequently led modern scholars to consider this literary/religious choice of reference as empirical and chronological evidence, thereby ignoring any contradicting archaeological evidence). See: Fogelin (2015, 14-15; 111-120; 158-169).
} 
hopes to have shown, this particular dataset strongly indicates that the Karakorum Mountains were not quite so impassable in either empirical or theoretical sense.

Acknowledgements This research project and its output are supported by the Byvanck Postdoctoral Fellowship, Leiden University. The author wishes to thank the organizers of The Rise and Fall: Environmental Factors in the Socio-Cultural Changes of the Ancient Silk Road Area workshop in Kiel 2017, in particular Dr. Liang Emlyn Yang, for inviting my contribution. I am indebted to Prof. Harald Hauptmann for sharing his substantial knowledge and insights concerning the Karakorum rock carvings and assisting me greatly in acquiring the documentation and rapports from the Heidelberg Academy campaigns. My thanks are also due to Dr. Bryan Miller for sharing his ideas and putting me in touch with Hauptmann. I am grateful to Prof. Miguel John Versluys for his support and valuable advice, and to Milinda Hoo, Suzan van de Velde, and Lennart Kruijer for their feedback. Gratitude is due to my peer reviewers for notifying important points of correction in the first draft of this contribution.

\section{References}

Bandini-König, D. (2003). Die Felsbildstation Thalpan I: Kataloge Chilas-Brücke und Thalpan (Steine 1-30), Bearbeituing der Inschriften durch Gerard Fussman et al. (Herausgegeben von H. Hauptmann), Band 6. Mainz: MANP.

Bandini-König, D. (2005). Die Felsbildstation Thalpan II: Katalog Thalpan (Steine 31-195), Bearbeituing der Inschriften durch Oskar von Hinüber und Thomas O. Höllmann (Herausgegeben von H. Hauptmann), Band 7. Mainz: MANP.

Bandini-König, D. (2007). Die Felsbildstation Thalpan III: Katalog Thalpan (Steine 196-450),Bearbeituing der Inschriften von Gérard Fussman, Oskar von Hinüber, Nicholas SimsWilliams (Herausgegeben von H. Hauptmann), Band 8. Mainz: MANP.

Bandini-König, D. (2009). Die Felsbildstation Thalpan IV: Katalog Thalpan (Steine 451-811), Bearbeituing der Inschriften durch Philip T. Denwood et al. (Herausgegeben von H. Hauptmann), Band 9. Mainz: MANP.

Bandini-König, D. (2011). Die Felsbildstation Thalpan V: Kataloge Ziyarat, Thakot, Khomar Das, Gichoi Das, Dardarbati Das, Bearbeituing der Inschriften von Gérard Fussman, Oskar von Hinüber, Nicholas Sims-Williams (Herausgegeben von H. Hauptmann), Band 10. Mainz: MANP.

Bandini-König, D. (2013). Die Felsbildstation Thalpan VI: Kataloge Ba Das, Ba Das Ost, Gali, Gukona, Mostar Nala, Ke Ges, Ame Ges und Drang Da, Bearbeituing der Inschriften durch Gérard Fussman, Oskar von Hinüber und Nicholas Sims-Williams (Herausgegeben von H. Hauptmann), Band 11. Mainz: MANP.

Beckwith, C. (2009). Empires of the Silk Road: A history of Central Asia from the bronze age to the present. Princeton: Princeton University Press.

Behrendt, K. (2007). The art of Gandhara in the metropolitan museum of art. New York: Metropolitan Museum of Art Publications.

Bennmann, M., \& König, D. (1994). Die Felsbildstation Oshibat, mit Beiträgen von Gerard Fussman, Oskar von Hinüber und Nicolas Sims-Williams (Herausgegeben von H. Hauptmann), Band 1. Mainz: MANP.

Bhattacharya, C. (1977). Art of Central Asia (with special reference to wooden objects from the Silk Route). Delhi: Agam Prakashan Publishers.

Boardman, J. (2015). The greeks in Asia. London: Thames \& Hudson.

Bruneau, L. (2007). L'architecture bouddhique dans la vallée du Haut Indus (Pakistan): un essai de typologie des représentations rupestres de stūpa. Arts Asiatiques, 62, 63-75.

Bussagli, M. (1996) L'art du Gandhara. Paris. 
Carter, M. (1993). Petroglyphs at Chilas II: Evidence for a pre-iconic phase of Buddhist art in Gandhara. South Asian Archaoology, 1991, 349-366.

Cogley, J. G. (2017). The future of Asia's glaciers. Nature, 549, 166-167.

Cunningham, A. (1871). The ancient geography of India: The Buddhist period, including the campaigns of Alexander, and the travels of Hwen-Thsang. Cambridge: Cambridge University Press.

Dani, A. H. (1983). Chilas, the city of Nanga Parvat (Dyamar). Islamabad: University of Islamabad Press.

Faccenna, D. (1980). Butkara I (Swāt, Pakistan) 1956, Excavation Reports. IsMEO, 1-5.

Faccenna, D., \& Taddei, M. (1993). Memoirs and reports, Istituto Italiano per il Medio ed Estremo Oriente. IsMEO, 43, 1-4.

Fogelin, L. (2015). An archaeological history of Indian Buddhism. Oxford: Oxford University Press. Foucher, A. (1905). L'Art Gréco-Bouddhique du Gandhara. Paris: Paul Geuthner.

Fussman, G. (1993). Chilas, Hatun et les bronzes Bouddhiques du Cachemire. Antiquities of Northern Pakistan, Reports and Studies, 2, 1-60.

Fussman, G. (1994). Chilas-Thalpan et l'art du Tibet. Antiquities of Northern Pakistan, Reports and Studies, 3, 57-72.

Fussman, G., \& Bandini-König, D. (1997). Die Felsbildstation Shatial, mit Beiträgen von Oskar von Hinüber, Thomas O. Höllmann, Karl Jettmar und Nicolas Sims-Williams (Herausgegeben von H. Hauptmann), Band 2. Mainz: MANP.

Fussman, G., \& Jettmar, K. (1994). Antiquities of Northern Pakistan, reports and studies 3. Mainz: Verlag Philip von Zabern.

Geerken H. H., \& Bräker, A. (2017). The Karakoram highway and the Hunza Valley 1998 (on demand).

Hauptmann, H. (2008). Rock art in the upper Indus region. In C. Luczanits (Ed.), Gandhāra, the Buddhist heritage of Pakistan: Legends, monasteries, and paradise (pp. 352-357). Mainz: Phillip v. Zabern.

Hauptmann, H. (2009). Felsbilder und Ischriften am Karakorum Highway. Heidelberg: Heidelberg Academy.

Hill, J. E. (2009). Through the jade gate to Rome: A study of the Silk Routes during the late Han Dynasty \& annotated translation of the Chronicles of the Western Regions in the Hou Hanshu. Queensland: Create Space Independent Publishing.

Jettmar, K. (1985). Zwischen Gandhara und den Seidenstrassen, Felsbilder am Karakorum Highway: Entdeckungen Deutsch-Pakistanischer Expeditionen 1979-1984. Mainz: Verlag Philip von Zabern.

Jettmar, K. (1989). Antiquities of Northern Pakistan, reports and studies 1. Mainz: Verlag Philip von Zabern.

Jettmar, K. (1993). Antiquities of Northern Pakistan, Reports and Studies 2. Mainz: Verlag Philip von Zabern.

Klimburg-Salter, D. (1989). The kingdom of Bamiyan: Buddhist art and culture in the Hindu Kush. Naples/Rome: Istituto Universitario Orientale.

Kotera, T., Maeda, K., \& Miyaji, A. (1971). Bamiyan: Report of survey in 1969. Nagoya: Nagoya University Press.

Liu, X. (2010). The Silk Road in world history. Oxford: Oxford University Press.

Maillard, M. \& Jera-Bezard, R. (1994). Les stupas de Kuberavahana à Chilas et Thalpan. In G. Fussman, \& K. Jettmar (Eds.), Antiquities of Northern Pakistan, reports and studies (pp. 173-200), 3.

Mairs, R. (2014). The Hellenistic Far East: Archaeology, Language, and Identity in Greek Central Asia. Berkeley.

Marshall, J. H. (1975). Taxila: An illustrated account of archaeological excavations carried out at Taxila under the orders of the Government of India between the years 1913 and 1934. Cambridge: Cambridge University Press.

Miller, B. K. (2014). 'Xiongnu 'kings' and the political order of the steppe empire. Journal of the Economic and Social History of the Orient, 57, 1-43. 
Miller, B. K., \& Brosseder, U. (2017). Global dynamics in local processes of Iron Age Inner Asia. In T. Hodos, et al. (Eds.), The Routledge handbook of archaeology and globalization (pp. 470-487). Oxford: Routledge.

Neelis, J. (2011). Early Buddhist transmission and trade networks: Mobility and exchange within and beyond the northwestern borderlands of South Asia (Dynamics in the history of religion). Leiden: Brill.

Neelis, J. (2014a). Networks for long-distance transmission of Buddhism in South Asian Transit Zones. In T. Sen (Ed.), Buddhism across Asia: Networks of material, intellectual and cultural exchange (pp. 3-17). Singapore: Institute for Southeast Asian Studies.

Neelis, J. (2014b). Localizing the Buddha's presence at wayside shrines in Northern Pakistan. In P. Wick \& V. Rabens (Eds.), Religions and trade: Religious formation, transformation and cross-cultural exchange between east and west (pp. 45-64). Leiden: Brill.

Olivieri, L. N. (2013). Rock shelters of the Swat-Malakand from the bronze age to Buddhism. Materials for a tentative reconstruction of the religious and cultural stratigraphy of ancient swat. Berlin: Freie Universität.

Poo, M. C., Drake, H. A., \& Raphals, L. (2017). Old society, new belief: Religious transformation of Rome and China ca. 1st-6th centuries. Oxford: Oxford University Press.

Rüpke, J. (2016). On Roman religion: Lived religion and the individual in ancient Rome. New York: Cornell University Press.

Stein, M. A. (1944). Archaeological notes from the Hindu Kush region. Journal of the Royal Asiatic Society of Great Britain and Ireland, 1, 5-24.

Thewalt, V. (2008). Stūpas und verwandte Bauwerke in Felsbildern der Stationen Chilās I, Chilās II und Oshibat am Indus (Nordpakistan). Heidelberg: Heidelberg Academy.

Van Aerde, M. E. J. J. (2018). Revisiting Taxila: A new approach to the Greco-Buddhist archaeological record. Journal of Ancient West \& East, 17, 203-229.

Verardi, G., \& Filigenzi, A. (2003). Maurizio Taddei on Gandhara, collected articles. Naples: Università degli studi di Napoli L'Orientale.

Von Hinüber, O. (1989). Brahmi inscriptions on the history and culture of the Upper Indus Valley. In K. Jettmar (Ed.), Antiquities of Northern Pakistan, Reports and Studies (pp. 41-72), 1.

Von Hinüber, O. (1989). Buddhistische Inschriften aus dem Tal des Oberen Indus. In K. Jettmar (Ed.), Antiquities of Northern Pakistan, Reports and Studies (pp. 73-106), 1.

Yu, Y. (1967). Trade and expansion in Han China. Berkeley: University of California Press.

Yusuf, S. (2011). Threatened rock carvings of Pakistan. Dawn, May 18 (digital issue: https://www. dawn.com/news/629659/basha-dam-threatens-thousands-of-ancient-rock-carvings).

Open Access This chapter is licensed under the terms of the Creative Commons Attribution 4.0 International License (http://creativecommons.org/licenses/by/4.0/), which permits use, sharing, adaptation, distribution and reproduction in any medium or format, as long as you give appropriate credit to the original author(s) and the source, provide a link to the Creative Commons license and indicate if changes were made.

The images or other third party material in this chapter are included in the chapter's Creative Commons license, unless indicated otherwise in a credit line to the material. If material is not included in the chapter's Creative Commons license and your intended use is not permitted by statutory regulation or exceeds the permitted use, you will need to obtain permission directly from the copyright holder. 